\title{
The effect of using harmony and building teching on same physical shill and psychological variables and prep, stageat P.E class
}

\section{Dr/ Sawsan Hosny Mahmoud}

\section{Abstract:}

Throughout the researcher work in supervision of physical education lesson in schools around Egypt, she found out that the applied class with its known parts; warm up, fitness, gymnastics, and then cool doesn provoke or foresee the talent and creativity of the pupil.

Moreover, time is wasted during alternating from one part to another, or during the same part while changing apparatus used or changing places ......Etc.

In other words, the researcher observed that the achieved and creative as well as time sequences are neglected in the set pattern of physical education lesson.

Hence, the researcher was concerned by breaking this stative pattern, by many previous successful attempts to be followed by this research.

The first attempt was by changing the introduory part (Heatingpart) by some. (Tae boo) movements program, and it resulted in positive statistics on those who were subjected to practice this program.

This motivated the researcher to change the set pattern of the lesson designed for primary stage by a program of physical education lesson which also successfully proved statistically positive.

Thus, the researcher tried through this study to use the "building and harmony technique" in developing some of the physical, skills and psychological variables for girl pupils in prep, stage.

\section{Key words}

The effect of using harmony and building teching on same physical shill and psychological lvariables on dprep, stageat P.E class. For the researcher summed the title and exchanged Build \& Harmony instead of cooperation \&construction. Prep. Stage (Preparatory stage at schools covering the form (12-15) .

\section{Introduction:}

Education process aims to achieve the purpose of educational process through focusing on the educated

person as far as his needs and personal trends are concerned. Hence, the way to accomplish this purpose is to achieve the 
goals of the educational process. The physical education lesson is the core of the physical education school program.

The physical education lesson is the core of the physical education school program it is the most secured method to pass the educational experience to pupil.

It is the part through which all pupils benefit equally as it is considered the only compuelsory activity. It is subjected to specified methods each is concerned with specified educational level, which permit the opportunity to practice the sportive activity for all pupils.

Dr. Gamal El Adaway and other (2001) pointed out that the physical education lesson is compuelsory meal digested by all pupils, it should combine all necessary healthy elements.

It should also be tempting for all pupils to devour, and also physical education lesson should provide different experience to reach certain level of excellence.

The physical education lesson is considered the leisure time activity for pupils as it directs them to the right track and improves the social and psychological aspect of character as well selfconfidence.

The researcher have participated in many attempts to change the formation and components of physical education lesson, as it an educational experience which aims at achieving the methods through mutual activity between pupils and teachers.

The opinion changed or varied around the formation of the lesson.

In other words, according to some point of view; it is a scntific component, Dr. Enial Farrag (1983) noted that the lesson consists of a group as well as competitions, whereas Dr.Hassan Maoawad (1989) pointed out that the physical education lesson is formed of intoductroy, basic sportive activities educational activity.

Dr .Afaf Ebd 1Karim (1993)divided the lesson to introductory (overture) and general sportive achievement, educational part, practical part and final part, in accordance with Dr.Mowad. This is the 
actual definition a cknowledge for physical education lesson. However, Dr.Khaed Nabil kaeidr (1996) divided the physical education lesson into four partition; the warming up or heating, the physical preparation (group games), competitive activates, final.

These divisions ant icipates that of Moawad And Abdel Karim.

However, Dr.Makarem Abou Herga Dr.Mohamed Zaglouol (1998) and Dr.Nelly Ramzy and Dr.Nahed Saed(1998) and Dr.Gamal el Adawy (2000) agreed that physical education lesson consists of three main parts; introductory, main and final.

This is the final acknowledged definition of physical education lesson for prep stage.As for the division of the lesson is concerned, there were several attempts through years to develop. Modify, or verifying the physical education lesson either by increasing its output as done by Dr. Zeinab Omar (1982) other changes part of the lesson by another as Dr. Nadia Ali (2006). Where as others used the method education Polly (1994),
Thaxton (1999), Nadia Ali (2007).

The researcher found out that the physical education lesson with its current formation included time waste and less benefiting for its part. It also doesn't lead to elevation of kinetic level or even discovery. Moreover, the lesson consists of three or four separated parts which lack links and connectivity

.Hence, this motivated the researcher to consider new educational methods aiming to overcome this unlinked divisions.

Thus, the researcher accomplished methods surveys as far as her readings about all elements related to the development of physical education lesson.

As far as figure and formation are concerned, the researcher also surveyed set methods of physical education lesson at prep. Stageschools.

Eventually, the researcher concluded that the method of "build and harmony'1 is a way to avoid some problems e.g. links among parts. Thus this research is an attempt to apply this method or technique in 
physical education lesson for girls in prep.

Stage .Aiming to discover its affectivity in developing some physical as wellskilful and psychological elements.

The researcher by applying this techniquebelieves that it will not only improve the health, capability, power, social and psychological aspects, but also helps to discover the talented aspects and create new generations of promising athletes; The suggested lesson depends basically on "unity" in other words, it circulates around one angel namely; the kinetic ability, theeducational subject. The same purpose; these activities should be general.

As an illustration, the researcher suggests that the basketball lesson is divided into two groups:(1)Harmonic and introductory activities related to basketball(knowna sharmonic ,intellectual and psychological preparation.(2) Building and training activities related to basketball these activities mingled by knowledge, information, application, practice, building, progression and connecting the movement skills in the physical education lesson.

Teaching by using these methods is based on challenging the girls selfabilities and motivate the achieved participants and providing full opportunity for selection and innovation as well as freedom, taking in consideration their physical capability. In order to apply this method, the pupil should have at least knowledge of the basics of basketball, Volleyball and Athletic. They should have practiced some of the, activities included in the practice and training of the above.

Thus it starts with knowledge and springs to elevation, connection and innovation.According to the previous, researcher would like to exam the method of movement education better than classic method.

Hypothesis: There are positive differences between experimental and controlled groups in pre and post measurement

(1) Between the set wellknown program or pattern of training which was applied to the controlled group 
and the technique of "building and harmony was applied to experimental group.

(2) There are positive differences between experimental and controlled groups in pre and post measurement in some of the basic skills variables in basketball, volleyball ,and athletics.

There are positive differences between the pre and post measurements in tutoring some psychological variables (self-esteem and selfconfidence) in favor of experimental group.

\section{Procedures}

\section{Method:}

The researcher applied the experimental method by using pre and post measurements for research samples.

\section{Research Sample:}

The researche rused for a research sample, which consisting of(40)girls from Pyramids Language School. The sample was divided into' two group seach consistsof(20)students. The researcher applied the method of cooperation and constructionin P.E. lesson to the first 20 girl group forming the experimental group,whereas the researcher applied to the second group namely the controlled one the ordinary P .E. lesson technique.

The researcher performed similarity for all research sample and equilibrium between the experimental and controlled groups in all the research variables. The researcher reached the conclusion that

(a) The sequence averages for the general research sample (in the variables of age, weight, length, cleverness) were within the limits of +3 I -3 , This reveals that all the society of researchsample is normal, straight one, as far as these variables are concerned.

(b) The sequence aspect for the research sample in physical skill and basic physical skills variables for basketball volleyball, and athletics and the psychological aspect were limited between $+3 /-3$ which proves that the research society is normal balanced one.

(c) It appears that there are

no significant differences between the media torsdegree between the experimental and controlled 
groups in there search variables and basic physical skills for (Basketball, Volleyball, and athletics) and the psychological variables. This indicates that there are adequacy for both groups for these variables

This results display in the table (1) attached.

\section{Research tools}

(A) The researcher applied and executed number of lessons using the method of cooperation and construction in physical education activities in the set courses for girls, also she applied the same activities on the controlled sample but within the pattern of standard lesson.

(B) Number of tests to measure theselected physical alternates.

(C) Number of tests to measure the skill level of the activities included in the research.

(D) The tests of self-esteem and self-confidence as psychological variables.

The researcher concluded that method of cooperation and construction in physical education lesson was effective in the development of some of the physical,skills, and psychological alternates better than the standard physical education lesson form. Moreover, the differences were statistically positive in favor of the lesson of cooperation and construction in all measured variables. (All tools at the Appendix).The researcher made asurvey study during the period from 5-20 January 2014 before mid-year period to exam and to ensure the following:

- Theresearchsocietyofassi stantsarewelltrainedinperformi ngresearchmeasurement.

- To determine the measurement location.

- The availability of equipments.

\section{- To}

determinetestduration and itsrelevance to the evaluation.

- $\quad$ Executing the measurements for physical variable on Sunday 16/2Monday 17/2/2014.

- $\quad$ Executingthemeasureme ntsforfundamental skills variable for Basketball Volleyball and athletics Tuesday 18/2, Wednesday 19/2/2014.

- Apply the two tests of self-esteem and self-confidence for all on Thursday 20/2/2014. 
The application of theprogram

(1) The program execution took (10) weeksduration, covering the period from $23^{\text {nd }}$ of February 2014 to 30thApril 2014 (2 lessons per week) The duration of each activity was determined as follows:

a) (4)Weeks to apply Basketball activity for both controlled and experimental groups.

b) (4) Weeks to apply Volleyball activity for both controlled and experimental groups.

(2) weeks to apply Athletic activity for both controlled and experimental groups.

\section{N.B. During the above;}

The experimental group was subjected to the proposed program"Build\& Harmony"; the lesson focuses on one topic activity which is Basketball in number (a), Volleyball in Number (b) and Athletics in (c).

Where as, the controlled group was subjected to the set lesson which consists of (warmup, fitness,rhythmic gymnastics, educational activities and the closing of the lesson). Basketball, Volleyball, or Athletic are included in the educational part of the lesson. After applying the program on both :There search erapplied the post measure menton both groups from4/5-8/5/2014.

The researcher selected .05 as the level of significant.

The tables (2), (3), (4) show the result of the measurements for both groups. attached.

\section{Discussion:}

In accordance with the results achieved by the researcher within the limits of the research sample and the time direction of the research, the researcher concluded the following:The researcher performed number of statistic measurements; The pre and post measurements for the controlled and experimental groups in physical variables and the means and standard deviation, positive differences in pre and post measurements for experimental and controlled groups in physical variable test, the positivity between the pre and post measurements for the controlled and experimental groups in testing some basic skills (in basketball, volleyball and athletics) , the means and standard deviation, positive 
differences between pre and post measurements for the controlled and experimental group in testing thebasic skills (in basketball, volleyball and athletics), the means and standard deviation and positive differences

(1) between pre and post measurements for the experimental group and controlled group in the selfesteem and self-confidence tests and finally the means and standard deviation and positive differences between pre and post measurements for the experimental and controlled groups in the psychological variables (self-esteem, selfconfidence).

(2) From the above, the differences between pre and post measurement were statistically positive in favour of the experimentalgroup in which the resear rapplied the lesson using "build and harmony technique".
(3) The lesson in its new form improved the elements of power, ability, agility, balance, coordination ,accuracy ,speed ,muscular endurance and cardiovascular ,better than the known pattern. There are also improvement in the skill level of basketball,volleyball,and athletics and the psychological measurements of self-esteem and self-confidence for pupils.

\section{Recommendation:}

- $\quad$ Applying the "Built and Harmony Technique" in secondary and elementary stages at schools in Egypt.

\section{The urge for} more application of thenBuilt and Harmony Technique"in wider scale of researches.

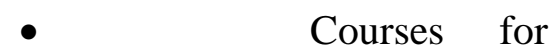
teachers to enable them to know and comprehend the different new method in physical education lesson, thus encouraging them to innovate. 